\title{
FINITE ELEMENT ANALYSIS OF MINIPLATE FOR POST-FRACTURE FINGER REHABILITATION DEVICE
}

\author{
Nanang Qosim ${ }^{1}$, Ratna Monasari ${ }^{2}$, Zakki F. Emzain ${ }^{3}$, Lutfi Hakim ${ }^{4}$, Ali Sai'in ${ }^{5}$ \\ Department of Mechanical Engineering, Politeknik Negeri Malang ${ }^{1,2,3}$ \\ Department of Electrical Engineering, Politeknik Negeri Banyuwangi ${ }^{4}$ \\ Department of Mechanical Engineering, Politeknik Negeri Semarang ${ }^{5}$ \\ nanangqsm@polinema.ac.id ${ }^{1}$
}

Received : 2 October 2020, Revised: 10 November 2020 , Accepted : 11 November 2020

\begin{abstract}
Miniplate plays an important role as one of the implant components used as a rehabilitation device for a post-fracture finger. In this study, an analysis was carried out to determine the strength of the miniplate design made from Ti-6Al-4V titanium alloy material. Simulation and analysis were carried out using the finite element method. The given input for modeling tensile and bending loads determined von Mises stress, kinetic energy, strain energy, and internal energy. The analysis showed that uneven von Mises stress and strain distribution have occurred. The critical concentration of stresses was located at the center of the miniplate and these values were a lot lower than the yield stress of Ti-6Al-4V.
\end{abstract}

Keywords : Miniplate, Implant, Finite Elemen Method, Fracture, Finger.

\section{Introduction}

Fracture is a break in the continuity of bone cells in the radius as a result of trauma (accident) so that the bone becomes two or becomes several pieces of bone. Most fractures are caused by trauma where there is excessive pressure on the bone, either direct trauma or indirect trauma (Sjamsuhidajat \& De Jong, 2019). Common types of fractures include stable fracture, compound fracture, transverse fracture, oblique fracture, and comminuted fracture (Haughton, Jordan, Malahias, Hindocha, \& Khan, 2012). One of the most common fractures is a fracture in the fingers of both the hands and feet caused by traffic accidents, sports, work accidents, and others. To rehabilitate the fracture in the finger, the implantation of the miniplate, as shown in Fig. 1, is the management that must be done (Demino, Yates, \& Fowler, 2019; Lögters, Lee, Gehrmann, Windolf, \& Kaufmann, 2018).

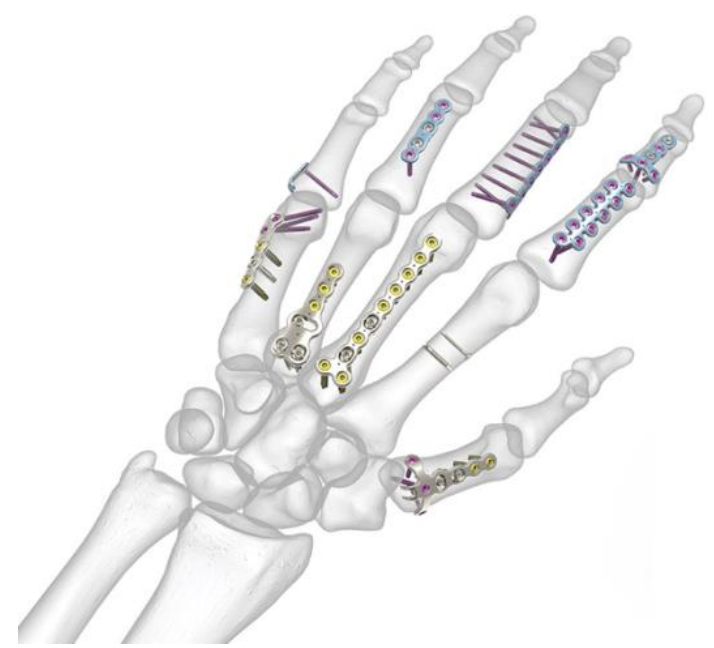

Figure. 1. The implantation of miniplate for post-fracture finger rehabilitation (Acumed, 2020)

To achieve success in post-fracture finger rehabilitation, the main factors to be considered are the implant design, material properties, and appropriate surgical techniques (Malau et al., 2019). The previous study showed that the newly designed on plant miniplate anchorage system was effective, easily implanted, and minimally invasive (Liu, Qu, Jiang, Zhou, \& Tang, 2016). 
Ridhi attempted to use a 3-Dimensional plating system and revealed that it was a suitable method for the fixation of simple mandibular angle fractures (Ridhi, 2012). To minimize clinical failures of the miniplate and numerically analyze the design, the finite element method (FEM) has been used as it is the most widely used method to acquire performance data of new miniplate designs (Albogha, Mori, \& Takahashi, 2018; Arbag, Korkmaz, Ozturk, \& Uyar, 2008; Korkmaz, 2007).

This study purposed to develop a patient-specific design of miniplate for post-fracture finger rehabilitation by investigating numerically the bending strength and tensile strength using FEM, in accordance with Indonesian anthropometry. There are two major advantages of the design developed. Firstly, the appropriate stress distribution of the implant is supposed to diminish the wear on the implant surface and the risk of early loosening as well. Second, the appropriate ratio of the strength-to-weight based on the patient's condition will minimalize the postoperative treatment and the failure of implantation as well.

\section{Research Methods}

The design process was carried out using CAD (Computer-Aided Design) software. The design made referred to the products on the market which were then modified based on the recommendations of the surgeons. The design was then analyzed by stress analysis. For this study, we used the FEM, namely the displacement formulation to calculate the component displacement, strain, and pressure under internal and external loads. The geometry under analysis used tetrahedral (3D), triangular (2D), and beam elements, and was solved by either sparse solvers or direct iterations. The failure condition used was the von Mises theory, which is an equation that takes each value of shear stress and the principal stress, and produces a "von Mises stress value" which can be compared with the yield strength of the material. If the result of the von Mises stress value is greater than the yield strength, then the part fails according to the criteria, but if the result is less than the yield strength, then the part is said to be in the safe criteria, and does not fail. The simulated tests to determine the mechanical strength included tensile tests and bending tests. In this study, it was assumed that the load that occurred on the fingers normally was $50 \mathrm{~N}$ for tensile loads and $10 \mathrm{~N}$ for bending loads. This condition was then assumed to be the boundary conditions.

Furthermore, in this study, the given mesh type was a curvature type with a maximum size of 0.05 and a minimum of 0.01 with high quality. The size and quality of the mesh were adjusted to the geometric shape by considering the simulation time and the accuracy of the simulation results. The material used in this modeling was Ti-6Al-4V alloy with detail of mechanical properties as shown in Table 1. Titanium alloys have better properties than pure titanium itself. Ti6Al4V alloy (ASTM F136) and commercially pure titanium (CP Ti), grade 4 (ASTM F67) are the most widely used materials in the implantation field (Qosim, Supriadi, Shamsuddin-Saragih, \& Whulanza, 2018; Ratner, Hoffman, Schoen, \& Lemons, 2004). So that in this study, Ti6Al4V was used as the material for the miniplate.

Table 1. Mechanical properties of Ti-6Al-4V alloy

\begin{tabular}{cc}
\hline Parameters & Value \\
\hline Elements $(\mathrm{wt} \%)$ & balance Ti; 5.5-6.5 Al; 3.5-4.5 V \\
\hline Density $\left(\mathrm{kg} / \mathrm{m}^{3}\right)$ & $4429-4512$ \\
\hline Elastic modulus $(\mathrm{GPa})$ & $104-113$ \\
\hline Yield strength $(\mathrm{MPa})$ & $850-900$ \\
\hline Ultimate strength $(\mathrm{MPa})$ & $960-970$ \\
\hline Poisson's ratio & $0,31-0,37$ \\
\hline
\end{tabular}

\section{Results and Discussions \\ 4.1 Design of Miniplate}

The main focus in designing this prototype miniplate was how to get a rigid internal fixation. This aimed to get a good interaction between the miniplate, screw, and the bone. Fig. 2. is a design result that refers to several commercial products and inputs from surgeons. The design form is a straight, non-locking type miniplate with four holes. The choice of this design was based on the consideration of the ease of the production process if it would be continued into a mass- 
product. Another consideration was in terms of placement, which was expected to prevent the translocation of the miniplate when used in the fracture rehabilitation.
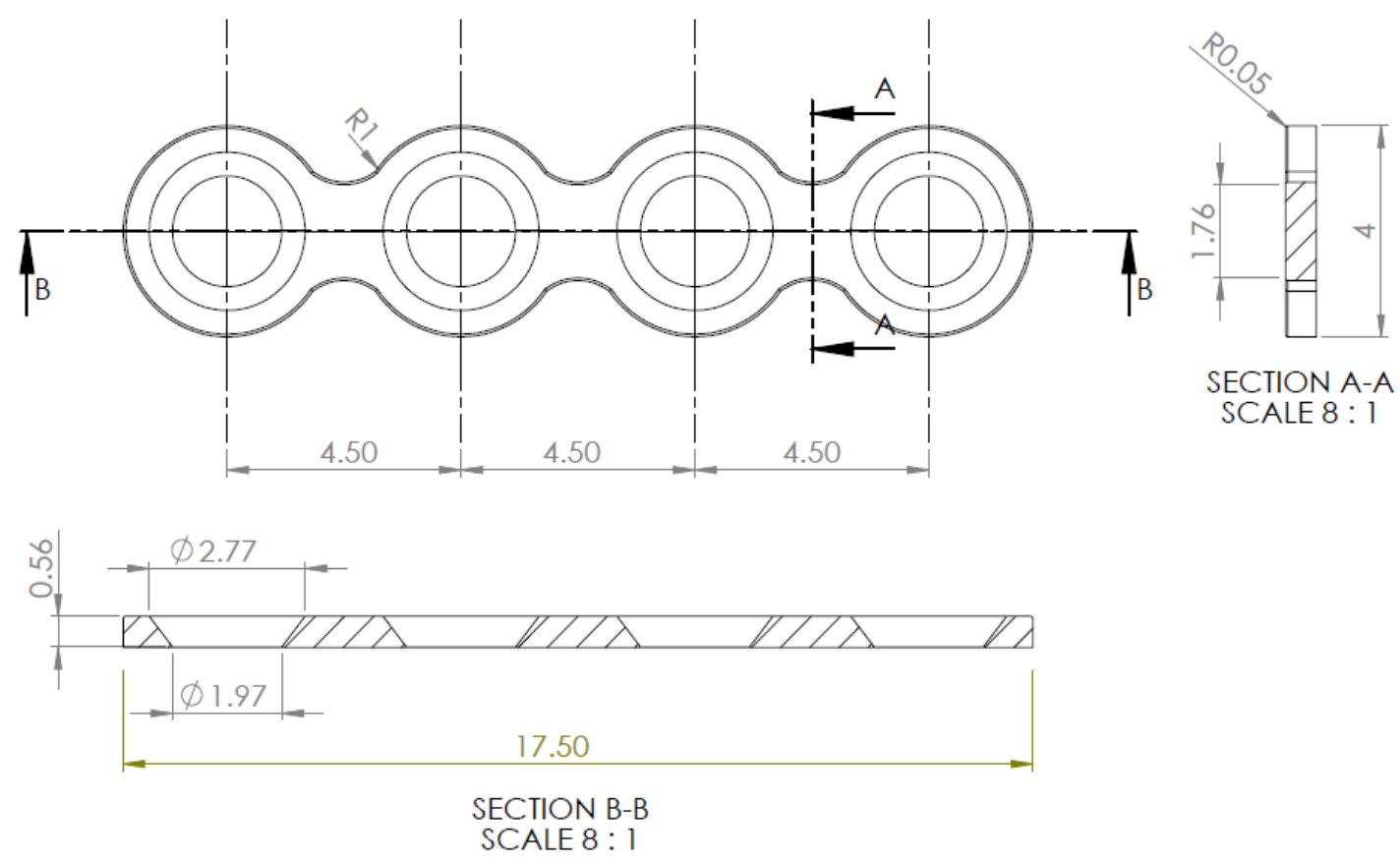

Figure. 2. Technical drawing of the miniplate design

\subsection{FEA Results}

In this FEA (finite element analysis), meshing was performed automatically using a specific mesh size range in the type of curvature with the maximum and minimum size of 0,05 and 0,01 , respectively, with high quality. Fig. 3 shows the meshing result used in this analysis with total nodes of 19051 and total elements of 10941.

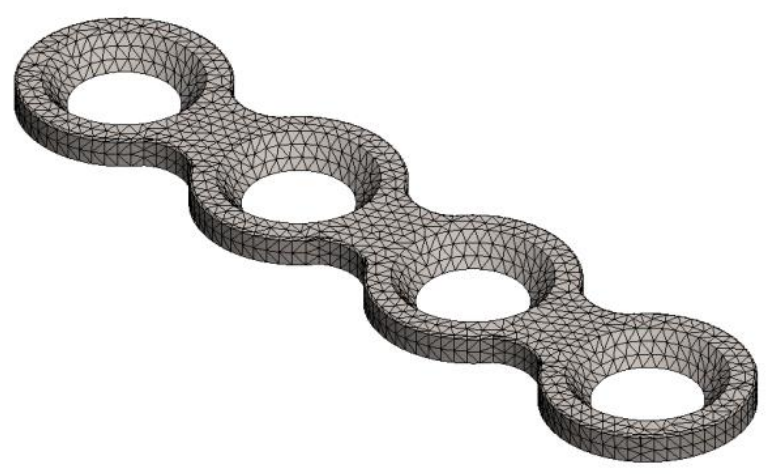

\begin{tabular}{|l|l|}
\hline Total Nodes & 19051 \\
\hline Total Elements & 10941 \\
\hline Maximum aspect ratio & 12898 \\
\hline
\end{tabular}

Figure. 3. Finite element discretization of the miniplate

Fig. 4a and 5a show the Von Mises stress distribution as the result of the computation. The stress values are represented by red to green colors that indicated from low to high, respectively. Stresses were calculated to size up the possibility of failure of the implant caused by the maximum load. Fig. $4 \mathrm{~b}$ and $5 \mathrm{~b}$ show the strain results from finite element analysis. The highest strain areas are located at the center of the load force distribution.

The simulation results of the tensile test with a load of $50 \mathrm{~N}$ showed that the four-hole miniplate was under stress with a maximum value of $245396000 \mathrm{~N} / \mathrm{m}^{2}$. This value was still below the yield strength of $827371000 \mathrm{~N} / \mathrm{m}^{2}$, so the miniplate was still safe for $50 \mathrm{~N}$ loads. As shown in 
Fig. 4c, the miniplate experienced the displacement of $0.0386 \mathrm{~mm}$. This value was considered very small, so it was considered that it would not affect the performance.

Furthermore, the simulation results of bending tests with a load of $10 \mathrm{~N}$ showed that the miniplate was under stress with a maximum value of $242758000 \mathrm{~N} / \mathrm{m}^{2}$ which was still below the yield strength of $827371000 \mathrm{~N} / \mathrm{m}^{2}$. The displacement experienced by the miniplate was 0.0849 $\mathrm{mm}$, as shown in Fig. 5c. This value was considered very small, so it was considered that it would not affect the performance.

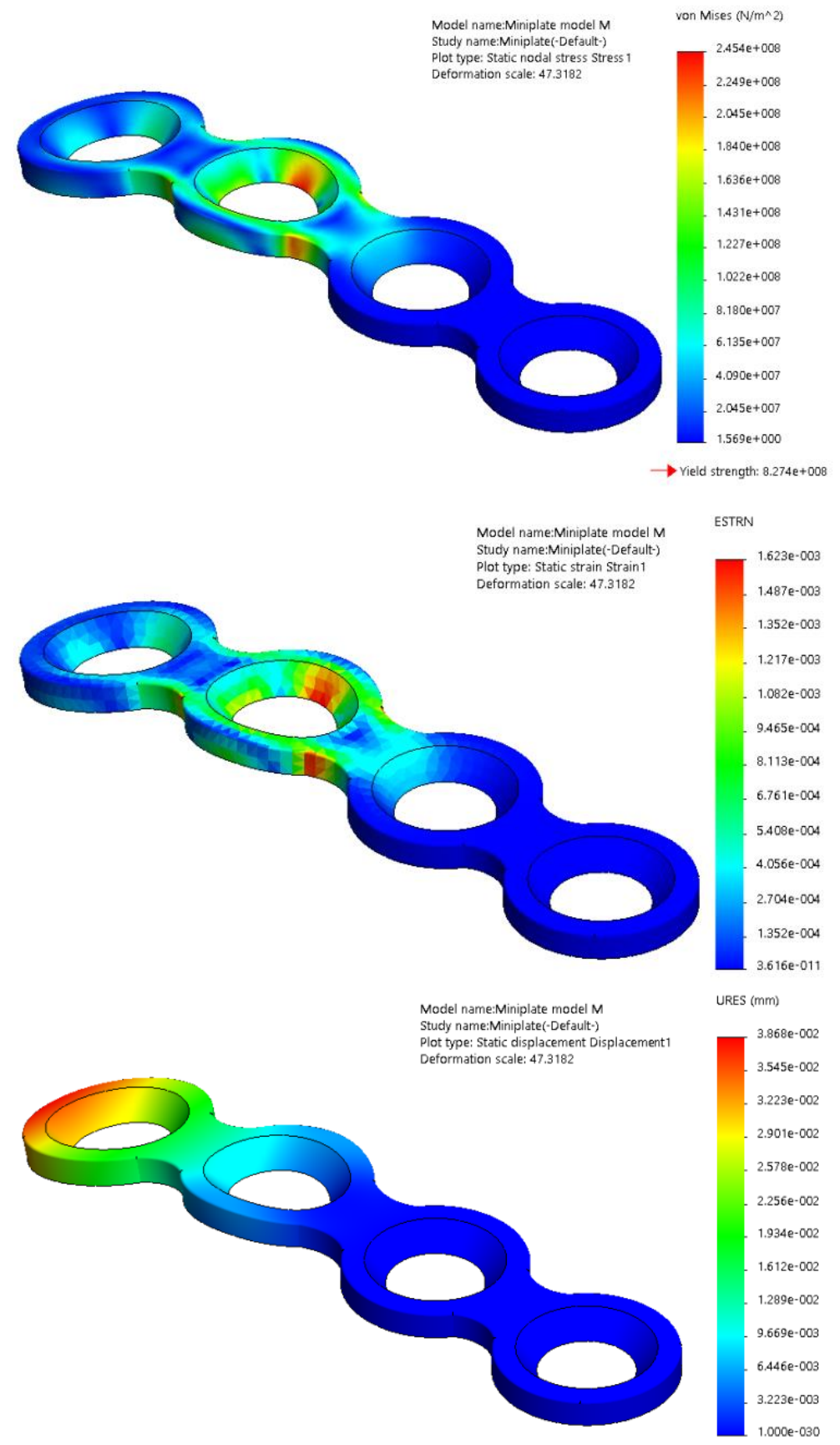

Figure. 4. FEA results of the tensile load 


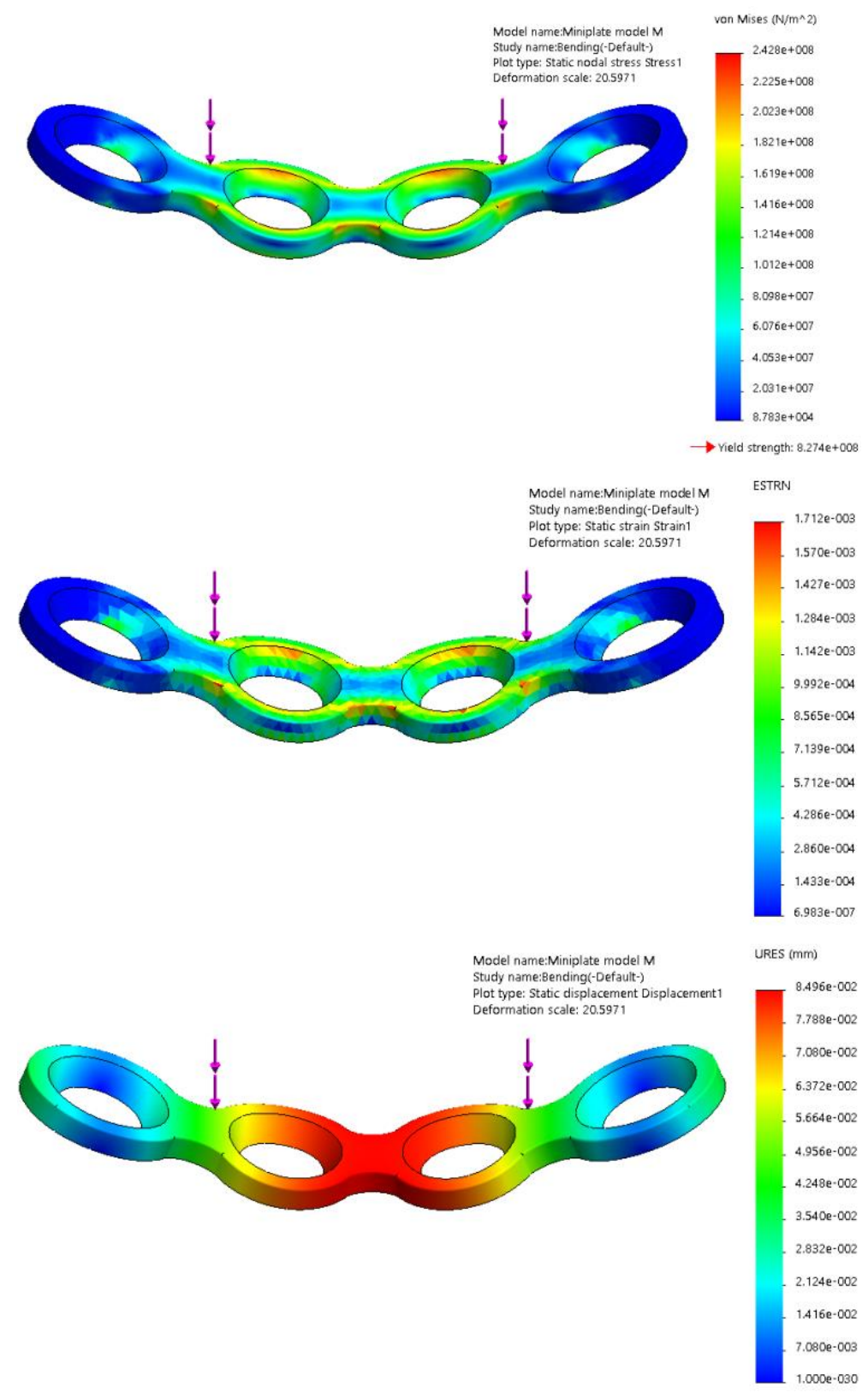

Figure. 5. FEA results of the bending load

\section{Conclusion}

The study of design and numerical analysis of miniplate for post-fracture finger rehabilitation device was successfully conducted. By applying a static load to the model, FEA results revealed uneven von Mises stress and strain distribution. The critical concentration of stresses was located at the center of the miniplate even though the stress values were a lot lower than the yield stress of Ti-6Al-4V. The displacements occurred also a lot low so that it was considered not to affect the performance.

\section{References}

Acumed. (2020). Hand Fracture System. Retrieved from https://www.acumed.net/

Albogha, M. H., Mori, Y., \& Takahashi, I. (2018). Three-dimensional titanium miniplates for fixation of subcondylar mandibular fractures: Comparison of five designs using patientspecific finite element analysis. Journal of Cranio-Maxillofacial Surgery, 46(3), 391397. 
Arbag, H., Korkmaz, H. H., Ozturk, K., \& Uyar, Y. (2008). Comparative evaluation of different miniplates for internal fixation of mandible fractures using finite element analysis. Journal of oral and maxillofacial surgery, 66(6), 1225-1232.

Demino, C., Yates, M., \& Fowler, J. R. (2019). Surgical management of proximal interphalangeal joint fracture-dislocations: a review of outcomes. Hand, 1558944719873152.

Haughton, D. N., Jordan, D., Malahias, M., Hindocha, S., \& Khan, W. (2012). Suppl 1: principles of hand fracture management. The open orthopaedics journal, 6, 43.

Korkmaz, H. H. (2007). Evaluation of different miniplates in fixation of fractured human mandible with the finite element method. Oral Surgery, Oral Medicine, Oral Pathology, Oral Radiology, and Endodontology, 103(6), e1-e13.

Liu, L., Qu, Y.-y., Jiang, L.-j., Zhou, Q., \& Tang, T.-q. (2016). Three-dimensional finite element analysis of a newly designed onplant miniplate anchorage system. Journal of Huazhong University of Science and Technology [Medical Sciences], 36(3), 422-427.

Lögters, T. T., Lee, H. H., Gehrmann, S., Windolf, J., \& Kaufmann, R. A. (2018). Proximal phalanx fracture management. Hand, 13(4), 376-383.

Malau, D. P., Utomo, M. S., Annur, D., Asmaria, T., Prabowo, Y., Rahyussalim, A. J., . . Amal, M. I. (2019, 2019). Finite element analysis of porous stemmed hip prosthesis for children.

Qosim, N., Supriadi, S., Shamsuddin-Saragih, A., \& Whulanza, Y. (2018). Surface treatments of ti-alloy based bone implant manufactured by electrical discharge machining. Ingeniería y Universidad, 22(2), 59-70.

Ratner, B. D., Hoffman, A. S., Schoen, F. J., \& Lemons, J. E. (2004). Biomaterials science: an introduction to materials in medicine: Elsevier.

Ridhi, V. (2012). Use of 3-Dimensional Miniplate in Mandibular Angle Fracture Fixation: A Clinical and Finite Element Study.

Sjamsuhidajat, R., \& De Jong, W. (2019). Buku-Ajar Ilmu Bedah. 